\title{
The Role of Visualisation in Data Handling in Grade 9 within a Problem-centred Context
}

\author{
Antonia Makina \\ University of South Africa \\ makina@unisa.ac.za \\ Dirk Wessels \\ University of Stellenbosch \\ dirkwessels@sun.ac.za
}

In the recent past, data handling has been neglected at secondary school level, perhaps partially due to the strong emphasis on developing arithmetic, algebra and geometry. For the first time, the South African curriculum includes substantial amounts of data handling at all grade levels. The introduction of more data handling in the secondary school curriculum in South Africa and the prevalence of many problems in the teaching of probability and statistics argues for a serious reconsideration of the way it is taught to the pupils. Currently this concern has been the focus of a call for reform in mathematics education by a body like the National Council of Teachers of Mathematics (NCTM) at all levels of schooling (NCTM, 1989; 2000). The importance of visualisation in mathematics, at all levels of mathematical problem solving is well documented in the literature (Bishop, 1989; Maher \& Alston, 1989; Moses, 1982; Wheatley, 1991) but almost nothing was done to appreciate visualisation in the learning of data handling. The paper therefore provides a qualitative examination from a Masters dissertation (Makina, 2005) of the role of visualisation in the learning of data handling. This is done through examining the thought processes involved by Grade 9 learners during visualisation while solving data handling tasks. Several roles of visualisation were identified and most were found to improve the critical and creative thinking of pupils during their learning of data handling. The results show that learners are likely to improve their performance in data handling if the awareness of the need to use visualisation creatively as a tool for understanding are highlighted.

My experience both as a classroom mathematics teacher and as a teacher educator indicates that generally data handling teaching is still teacher centred despite the strong calls for a move towards a student centred approach in a problem based atmosphere. It is still about dishing out rules that are rarely questioned, tasks that are textbook dependent and answers that should be either right or wrong. Another observation is students' understanding is dependent on their obtaining high or low marks that must come from repeating and re-repeating textbook exercises. We continually experience many of our mathematics teachers who teach mathematics in a very traditional expository way. They simultaneously constitute counterexamples in showing how to teach and how to do mathematics. In essence the teacher is translating the textbook into words and actions. Mathematics has more to do with reasoning than memorising facts and if we accept this then the processes they go through during problem solving should be respected. With the advent of a number of theories in mathematics (constructivism, etc.) that all encourage a vision of 
mathematics teaching in which students engage in inquiry and develop understanding of key concepts and practices, consideration of alternative approaches to the teaching of mathematics is necessary.

Occasionally when teachers work with students in class, the main task is to organise or develop teaching material and to help students construct new understandings based on the new knowledge in these materials. Through the use of formative assessments, teachers attempt to gain feedback into how well students are learning and into particular difficulties they might be having, followed by summative assessments to make a determination about overall learning that has been achieved. This however cannot be enough to guarantee successful teaching for understanding. Some ways to bridge the gap between learning and teaching have been suggested. For example Fennema and Carpenter (1998) suggested a general instructional model in which research based knowledge of students thinking is used to inform classroom instruction. In accordance with this view of Fennema and Carpenter, in this study visualisation is pursued to understand students' ways of thinking while solving problems so as to improve the teaching of mathematics. Teachers should take into account students' knowledge and thinking and recognise their limits of language. This paper raises an awareness of visualisation in the classroom as one of the approaches that aids in teaching of the subject mathematics with understanding. This paper argues that understanding the student's thinking during problem solving (visualisation) improves the teaching of mathematics. Therefore the research question is: What is the role of visualisation in the teaching of data handling? This paper carried this out using a bigger study (Makina, 2005) through determining the nature of the mental processes involved in problem solving, relating these processes to the defined processes of visualisation and identifying through these mental processes visualisation's role in the understanding of data handling.

\section{Data handling}

Data handling is a very special and important section of statistics. It is this section of statistics that takes a learner out into the real world of seeing data for him/herself, reflecting upon it individually or socially, and drawing conclusions from it. Data handling, according to Shaughnessy (1992, p. 470), is describing, organising and reducing, representing, analysing and interpretation of data. South Africa has taken a move towards introducing more data handling in the schools. Data handling has become one of the important sections of mathematics at all grade levels in South Africa and is also an important part of the mathematics curricula for primary and secondary school classes in many countries. The usefulness of data handling for daily life, its instrumental role in other disciplines, the need for a basic data handling knowledge in many professions, and the important role of data handling in developing critical reasoning have been highlighted (Franklin et al., 2005; Gal, 2002; Hawkins, Jolliffe, \& Glickman, 1991; Wild \& Pfannkuch, 1999). We live in a society that is being exposed to graphic images on an increasing basis. This exposure is part of a trend to graphic communication (Kress \& van Leeuwen in Gerber, BoultonLewis, \& Bruce, 1995, p. 77) which we cannot escape. The importance of data handling should therefore be followed by a great need to have it taught to the pupils with understanding.

In the recent past, data handling has been neglected at secondary school level, perhaps partially due to the strong emphasis on developing arithmetic, algebra and geometry. For the first time, the South African curriculum includes substantial amounts of data handling at all grade levels. The new curriculum that includes data handling appears to have been endorsed in South Africa by the Department of Education $(2002,2003)$ in a clear bid to improve the quality of statistics education to its citizens. The tendency towards a data-orientated teaching of statistics is shown in the curricular orientation for primary and secondary school levels where students are expected to design investigations, formulate research questions, collect data using observations, surveys, and experiments, describe and compare data sets, use and understand statistical graphs and measures, propose and justify conclusions and predictions that are based on data (e.g., Burrill \& Camden, 2006; Lajoie, 1998; NCTM, 2000; Scheaffer, 2006). Change in school curricula is seen as offering an existing opportunity to develop learners' statistical intuitions, to foreground the mathematical concepts embedded in statistical techniques, and to create contexts in which these can be linked to broader mathematical ideas of symbol use, reasoning and logical necessity (Ainley $\&$ Pratt, 2001).Though South Africa has now accommodated reasonably enough probability and statistics in the schools, there still exist a general lack of enthusiasm for the subject - a general lack of 
understanding of the subject and its teaching. Therefore the introduction of more data handling in the secondary school curriculum in South Africa and the prevalence of many problems in the teaching of probability and statistics argues for a serious reconsideration of the way it is taught to the pupils. There is need to provide a rich knowledge base for the teachers through professional development that can support the current reforms in the $2000 \mathrm{~s}$.

\section{Visualisation}

Mathematics, as a human and cultural creation dealing with objects and entities quite different from physical phenomena, relies heavily on visualisation in its different forms and at different levels. Visualisation is described from the definition of mathematics as a science of patterns (Eisenberg \& Dreyfus, 1991, p. 5). The mathematician seeks patterns in number, space, science, computers and in imagination. If mathematics is the science of patterns, it is natural to try to find the most effective way to visualise these patterns and learn to use visualisation creatively as a tool for understanding. On the other hand Cobb, Yackel and Wood (1991) take on the issue of visualisation as a dualism created between mathematics in learners' minds and mathematics in their environment, present in what they call 'the representational view of mind' which they find to be prevalent in mathematics education today. In the representational view of mind, the overall goal of instruction is to help learners construct mental representations that correctly or accurately mirror mathematical relationships located outside the mind in instructional representations. Hence the visualisation process is one which involves visual imagery with or without a diagram, as an essential part of the method of solution (Presmeg, 1985, p. 298). Presmeg (in Thornton, 2000, p. 254) lists five different kinds of visual imagery that she identified in her learners as concrete, pictorial imagery (pictures-in- the-mind), pattern imagery (pure relationships depicted in a visual-spatial scheme), memory images of formulae, kinesthetic imagery (involving muscular activity, e.g., fingers walking and dynamic (moving) imagery). Such is the diversity of different types of visual imagery. Kosslyn (1994, p. 23) describes visualisation as a cognitive process involving visual imagery in which images involved are either generated, inspected, transformed or used for mathematical understanding. There are micro-strategies within each of these general stages. It is these stages that were the cornerstones of the analysis of data that was done in the bigger study by Makina (2005). In this paper visualisation is characterised as both the product (visual image) and the process (Bishop,1989, p. 9) and offers a method of seeing the unseen. This paper emphasises visualisation as a mental process that utilises visual imagery in the solution of problems in data handling.

There are still many issues concerning visualisation in mathematics education, which require careful attention. In the current educational climate there are at least three reasons why the role of visualisation in school mathematics which includes data handling needs to be re-evaluated (Thornton, 2000, p. 251). The first is that the current trend that identifies mathematics with the study of patterns, together with the ready availability of hand-held technology that can easily develop a general rule for a given pattern, has the potential to improve mathematical thinking. The second is that visualisation can often provide simple, elegant and powerful approaches to developing mathematical results and solving problems, in the process making connections between different areas of mathematics. The third is the importance of recognising and valuing different learning styles, and of helping learners to develop a repertoire of techniques for looking at mathematical situations. Previously it was believed that the products of mathematical work are more important than the process of how the results are achieved, and as a result it is these symbolic representations that were often held in high esteem, with visual tools seen at most as transitory steps on the way to real mathematics (Thornton, 2000, p. 251). The whole process that leads to a mathematical result must now be appreciated. Appreciating the importance of visualisation, points to the need to use visualisation creatively as a tool for understanding. There is need to understand how pupils think during visualisation during problem solving in order to be able to teach data handling with understanding. It is important to listen to pupils since there is a difference between what we want children to learn and what they actually take from our lessons. Understanding the student's mind during problem solving (visualisation) improves the way a teacher gets closer to understanding his pupils. Therefore this paper analyses the important role of visualisation in the learning of data handling through the understanding of mental processes that take place during visualisation while Grade 9 pupils solve data handling problems. The research question was: What is the role of visualisation in the learning of data handling? This paper 
carried this out through determining the nature of the mental processes that are carried out during problem solving, relating these processes to the defined processes of visualisation (Kosslyn, 1994) and identifying through these mental processes the role of visualisation in the learning of data handling.

\section{Method}

In the main study (Makina, 2005) twelve Grade 9 learners was purposefully selected using a nonprobability sampling procedure in collaboration with the teacher of mathematics at a Secondary School. The distribution of the twelve pupils were as follows, four above average learners, four average learners and four below average learners and were selected by using previous class performance. This was done so as to be able to represent the type of thinking portrayed by learners of all abilities. Two sources of data were used for the investigation. These included handwritten responses from data handling tasks, and transcriptions of the audio-taped interviews. Appreciating the importance of the relationship between visualisation, critical and creative thinking points to the need to understand the mental processes that are involved during visualisation. All data were collected during organised one hour sessions which started with written responses from tasks, the marking of the written responses, followed immediately by the individual audio-taped interviews. The interviews were used to support data from handwritten responses so as to provide meaningful descriptions of the thought processes during visualisation. The tasks chosen for this research were selected since they had been previously used in researches to improve visualisation and could easily be adapted for use in the Grade 9 school classroom. The two tasks used are shown in Appendix B and are among some of the tasks used for the big study. The processes that occur during visualisation while Grade 9 pupils solved data handling tasks were analysed during the qualitative study and aided by Kosslyn's (1994) four stages of visualisation which are generation, inspection, transformation and use.

\section{Data analysis, results and discussions}

In this paper visualisation was investigated for the purpose of examining the role of visualisation for a better understanding of data handling by pupils. Through the use of Kosslyn's (1994) categories (see Appendix A), written responses and transcripts from the interviews were sorted based on the categories and rubrics. Within these categories of Kosslyn the thought processes involved during visualisation were described and recorded with the help of sub-categories. First and foremost pupils were able to "see the unseen" look into their minds. It was in their minds that all the processes of visualisation took place. The word 'see' here is used to refer to the mental images that the students were working on in their mind. It does not imply the 'see' that refers to vision. For example one learner gave the researcher this answer in Task 2 "I am trying to make a shape and I am thinking of a shape in my head. I am thinking of the dice." The images that resulted from the 'seeing' were only partly presented on paper. The conclusion here is that the whole process of visualisation can never be fully illustrated on paper, and the teacher has to probe for most of the processes for a better understanding of the pupils' thinking.

Major results of the mental processes experienced during visualisation are illustrated in the tables below. Tables 1, 2 and 3 give the mental processes that resulted from visualisation during problem solving. They were in turn associated with the process of visualisation suggested by Kosslyn (1994:3). The processes involved during problems solving are interrelated with each other. It is therefore impossible to draw a clear line of whether a process is a result of self-regulation, critical thinking or assessment etc. For example self monitoring, self-regulation can simultaneously cause rich generated images to be transformed for use. 
Table 1: Results of Task 1

\begin{tabular}{|c|c|c|}
\hline $\begin{array}{l}\text { Processes in } \\
\text { visualisation }\end{array}$ & $\begin{array}{l}\text { Mental processes during visualisation } \\
\text { identified during problem solving }\end{array}$ & $\begin{array}{l}\text { Processes involved } \\
\text { during problem solving }\end{array}$ \\
\hline Generation & $\begin{array}{l}\text { Looking at the network } \\
\text { Analysing the network } \\
\text { Defining words or nouns differently (e.g., what is a } \\
\text { geometric body) } \\
\text { Name geometric shapes from previous knowledge }\end{array}$ & $\begin{array}{l}\text { Analysis } \\
\text { Meta-cognition } \\
\text { Higher order thinking } \\
\text { Similarity/simile } \\
\text { Metaphoric }\end{array}$ \\
\hline Inspection & $\begin{array}{l}\text { Thinking what shape could be made from this network } \\
\text { Eliminate most of the geometric shapes identified } \\
\text { Images described in different ways but resulted in the same } \\
\text { shape on paper(see Example } 2 \text { below) }\end{array}$ & $\begin{array}{l}\text { Metaphors/simile } \\
\text { Divergent thinking } \\
\text { Self-monitoring } \\
\text { Critical thinking } \\
\text { Self-monitoring }\end{array}$ \\
\hline Transformation & $\begin{array}{l}\text { Movement from one shape to another mentally or through } \\
\text { drawing on paper (e.g., cuboid to a cube) } \\
\text { Movement from one name to another(different names } \\
\text { given to same objects to suit the wanted) }\end{array}$ & $\begin{array}{l}\text { Creativity } \\
\text { Meta-cognition } \\
\text { Similarity/Animation } \\
\text { Simile/metacognition }\end{array}$ \\
\hline Use & $\begin{array}{l}\text { Relating a mental image to a visual object } \\
\text { Labelling faces and identifying body to the cube }\end{array}$ & Metaphoric \\
\hline
\end{tabular}

Example 1 and Figure 1 justify the evidence of generation, inspection and then finally transformation that occurred in Task 1. A geometric body was described the way each pupil understood it from previous knowledge, also described as divergent thinking and comes from learners' higher-order thinking skills. Learner B's written work in Figure 1 shows a learner progressing from one shape to another and is evidence of an original image that was generated and went through a number of transformations achieved after inspection. Cubes were in some cases named as toy boxes or as a jack in the box.

\section{Example 1}

Learner I: A geometric body has air in it so I made a box.

Learner A: A geometric body has got sides all equal like it can form something eee....

Learner C: I discovered that a geometric body has a....should have space inside....

The self-monitoring process on the part of the learners played a role in the successful solution of their tasks and this is in accordance with Van den Berg (2004, p. 292) who advises that self-assessment or selfmonitoring enables critical and creative thinking processes. It also influences learners' responsiveness and plays a key role in determining how learners selectively attended during problem solving. During visualisation creativity, metaphors, analogies and animation are used to guide the reasoning process (Presmeg, 1992, p. 599). Teaching strategies based on analogies and metaphors move from the known to the unknown and from the concrete to the abstract. Task 1 also required the learners to draw on paper the shape that could be made from the net shape that was given. Learner I physically made a cube out of paper, glue and cello-tape so as to clarify for herself the shape that was made from the net shape.

Interviewer: You made a box with the sides $2 \mathrm{~cm}$ each?

Learner I: I thought maybe I was just supposed to identify what this thing could make.

Interviewer: So you didn't want to draw anything on paper? Its like the problem says: "on the plane piece of paper provided draw the image obtained by unfolding a geometric body."

Learner I: Yaa. Its like, to me, it was obvious. The problem was quite obvious to me. When I looked at the paper I could see that in this thing we could do something like this box which can be six sides which is $1,2,3,4,5,6$. So I thought maybe I could make this box (showing the researcher the box she had physically made from paper, glue and sellotape) 


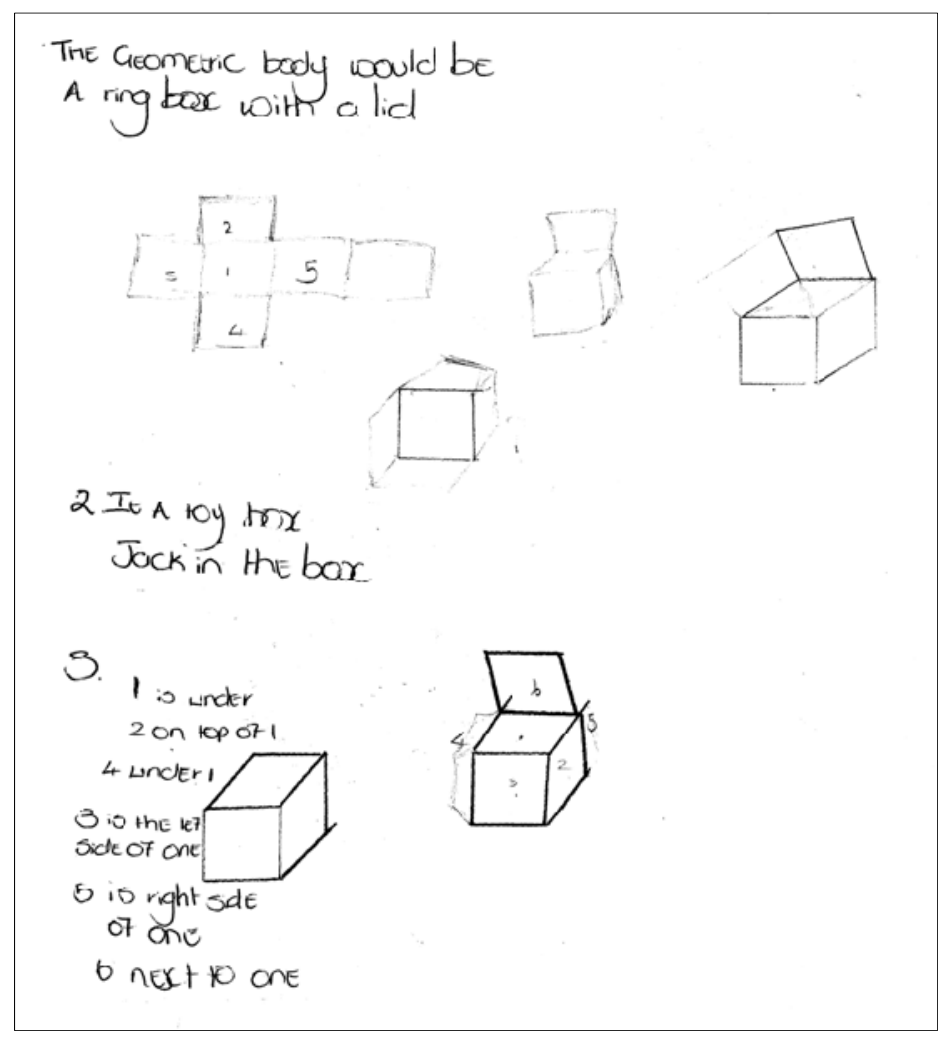

Figure 1: Learner B's written response to Task 1

The above result provided evidence that learners at times were not always able to draw or write what they could mentally imagine. In substantiating this Wheatley (1998, p. 10) maintains that care must be exercised in inferring imaging from children's drawings, as learners cannot always draw what they can image. It is therefore true that the mental images of some learners have to work hand in hand with physical visual images if they are to be better critical and creative thinkers. Visualisation enables the use of concrete objects as mental visual aids during problem solving. It must, however be noted that concrete materials are not used to transmit visual images to learners but are vehicles to encourage problem solving, knowledge construction and the development and use of different kinds of imagery (Vinner in Owens \& Clements, 1998, p. 215).

Table 2: Results of Task 2

\begin{tabular}{|c|c|c|}
\hline $\begin{array}{l}\text { Processes in } \\
\text { visualisation }\end{array}$ & $\begin{array}{l}\text { Mental processes during visualisation } \\
\text { identified during problem solving }\end{array}$ & $\begin{array}{l}\text { Processes involved } \\
\text { during problem solving }\end{array}$ \\
\hline Generation & $\begin{array}{l}\text { A new pattern formed to produce continuation } \\
\text { Looking at recorded data }\end{array}$ & $\begin{array}{l}\text { Meta-cognition } \\
\text { Creativity } \\
\text { Analysis }\end{array}$ \\
\hline Inspection & $\begin{array}{l}\text { Analysing the pattern (geometric/arithmetic/ both) } \\
\text { Check the differences/ratios between numbers }\end{array}$ & $\begin{array}{l}\text { Meta-cognition } \\
\text { Self-monitoring } \\
\text { Self-regulation } \\
\text { Critical thinking }\end{array}$ \\
\hline Transformation & $\begin{array}{l}\text { Moving from one sequence to another } \\
\text { Forming an approximate new pattern }\end{array}$ & $\begin{array}{l}\text { Assessment/self-monitoring } \\
\text { Creativity }\end{array}$ \\
\hline Use & $\begin{array}{l}\text { Prediction } \\
\text { Using the sequence to make previous and future prediction }\end{array}$ & $\begin{array}{l}\text { Divergent thinking } \\
\text { Estimation }\end{array}$ \\
\hline
\end{tabular}




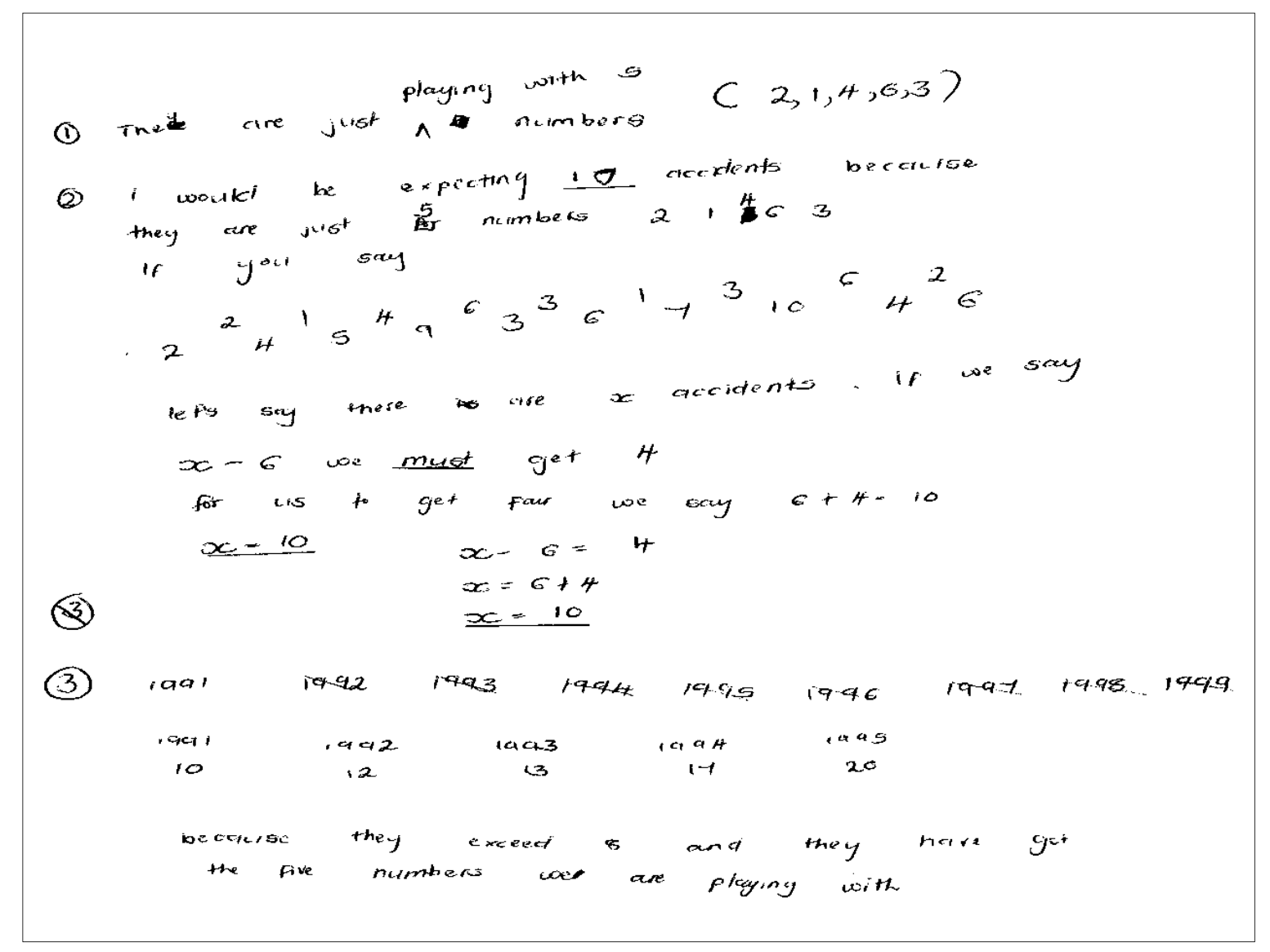

Figure 2: Learner E's written response to Task 2

Learner E developed her understanding of the problem and demonstrated increasingly abstract solution activity so that she could anticipate its results and was able to use the results to make future predictions through generalisation. Visualisation generated guided tactics, manipulations and decisions during problem solving and it therefore plays a central role in inspiring a whole solution beyond merely procedural but towards a more organised structure (Arcavi, 2003, pp. 216-233).

Task 2 allowed the learner to use their results of part two to make future predictions. Approximating the number of accidents after 1991 was done through the study of relationships that were identified in the first part of the question.

\section{Example 2}

Interviewer: How did you predict the number of accidents that occurred in 1992 ?

Learner F: I could see it by looking at these numbers. There was a pattern that I recognised and if this pattern is to continue, 1991 will get about 10 accidents ....

In the above Example 2, Learner F recognised the need to use the word "about" to give his answer of the number of accidents that occurred in 1991. Visualisation through higher-order thinking skills offers a method of estimation and therefore enables prediction of results in data handling. Critical and creative thinking during visualisation simplifies the learner's limitation of the mind in thinking, learning and problem solving activities. This occurs in this paper when the learner is involved with problems that involve patterns that are too long to determine the $n^{\text {th }}$ term or if there was need for them to make future or previous predictions. 
Table 3: Results of Task 3

\begin{tabular}{lll}
\hline $\begin{array}{c}\text { Processes in } \\
\text { visualisation }\end{array}$ & \multicolumn{1}{c}{$\begin{array}{c}\text { Mental processes during visualisation } \\
\text { identified during problem solving }\end{array}$} & \multicolumn{1}{c}{$\begin{array}{c}\text { Processes involved } \\
\text { during problems solving }\end{array}$} \\
\hline Generation & $\begin{array}{l}\text { Read the problem } \\
\text { Analyse the problem }\end{array}$ & $\begin{array}{l}\text { Analysis } \\
\text { Meta-cognition }\end{array}$ \\
& Use previous knowledge to think and name all representations & $\begin{array}{l}\text { Self-regulation } \\
\text { Divergent thinking }\end{array}$ \\
& Defining the idea of a poster & Self-monitoring/self- \\
Inspection & Pupils mentally think of conditions to draw all these & assessment \\
& representations & Self-regulation \\
& Eliminates most of the generated graphs at this stage & Critical and creative \\
& Checking the conditions for a nice poster & Meta-cognition \\
& & Self-monitoring \\
Transformation & Two or three graphs remain & Divergent thinking \\
& One is chosen & Estimation \\
\hline \multirow{2}{*}{ Use } & Prediction & \\
& Using the word about &
\end{tabular}

During interviews the learners were always explaining why they had to go one way with the solution and not the other. Learner D had this to say on the problem in Task 3:

I did not draw a bar chart because the smallest amount is zero for buses and there is two for taxis and the biggest amount is 48 for bicycles and then that would be just too much of a big gap and it would mean a big big chart so and then I thought a pie chart would be better.

Learners mentioned many graphs that came to their mind but resorted to only one. Learner $\mathrm{D}$ was able to give a reason why though she had thought of drawing a bar chart, she resorted back to a pie chart. Learner D explained about big gaps occurring between the discreet data of buses, bicycles, etc., that would not give a nice bar chart. The statistical reason given by Learner $\mathrm{D}$ showed her competence in the handling of data during problem solving. Visualisation involves identification and selection of suitable materials to use for a particular problem through reflective thinking. Reflective thinking is a process whereby one keeps on checking on one self's problem solving process. All the other graphs that were not relevant to the learner were eliminated mentally and the learner was able to explain why they did not warrant attention. In substantiating this idea it is said persons who reflect on their activities or solutions have control over their thinking and they are able to pursue several paths to the solution rather than being in limitations (Wheatley in Zimmerman \& Cumming, 1991, p. 535). Visualisation, apart from consolidating of knowledge and correcting of mistakes, induces important refinements in methods.

\section{Conclusion and recommendations}

More specifically the investigation revealed some major processes, namely reflection, self- monitoring, self-regulation, divergent thinking, meta-cognition, mathematical generalisation, critical and creative thinking, transformation, metaphors, similes, and animation which in turn identified visualisation as an important component of critical and creative thinking. All these major processes illustrated in Table 4 are interrelated and emerged as a result of learners describing what they were thinking while working on each of the data handling. 
Table 4: Summary of the major findings in this study

Visualisation

- allows self-monitoring during the problem solving processes.

○ influences students' responsiveness and plays a key role in determining how students selectively attended during problem solving.

$\circ$ allows the generation of different images for the same described shape.

o highlights to the discipline of mathematics the importance of key words.

o encourages the choice of non-routine and realistic problems by the educators and therefore plays a key role in determining how teachers select tasks to be used in the classroom.

- non-routine problems encouraged the pupils to inspect constructive useful mental images and therefore generate richer images.

$\circ$ at the service of problem solving, plays a central role in inspiring a whole solution beyond merely procedural but towards a more organised structure.

o saves as a support and illustration of essentially symbolic results by in effect providing a proof in its own right.

o during inspection it is responsible for the selecting and finalising of a quality type of visual image.

$\circ$ involves identification and selection of suitable materials to use for a particular problem

$\circ$ apart from consolidating of knowledge and correcting of mistakes, it induces important refinements in methods.

- acting as a cognitive technology helps simplify the limitation of the mind in thinking, learning and problem solving activities.

- whether in the form of concrete images, pattern images or dynamic images, has a key role to play in the development of students' mathematical power.

$\circ$ encourages estimation and therefore enables prediction of results in data handling.

Visualisation should serve as an integral part of teaching. The teacher must appreciate the process involved in reaching a solution rather than giving more attention to the end product in a solution. Teachers should understand the need for learners to communicate and interact with each other during data handling problem solving lessons. Successful solutions of problems during visualisation allow the learners to make connections between the data handling and many other areas of learners' experiences which include other subjects, other parts of the curriculum, mathematics learned in the past years and, above all, the real world. Educators should try and make the role of visualisation during problem solving clear to the learners if the learners are to take maximum advantage of it during problem solving. Engaging learners through the process of visualisation will enable learners to look at their own problem-solving processes critically. An understanding of the precise limitations of children's imagery could inform one how to use imagery in teaching. For example, if children's images are static, in that they cannot transform their images, then it would make sense to shift from trying to teach the them rules of transformation to teaching them the rules of formation. Similarly, if young learners are able to form images easily, while they have difficulty in maintaining them, it would be better to try to teach them by inducing a series of rather simple images and so forth. Teachers must be aware of the need to encourage the development of richer images during visualisation. Richardson (in Aspinwall, Shaw \& Presmeg, 1997, p. 315) suggests that if imagery is to be useful in problem-solving, it needs to be controllable. The role of visualisation is important in data handling and in all the other subjects of the curriculum, and it must therefore be appreciated and taken advantage of. The highest minds are probably those in which it is not lost, but subordinated, and is ready for use on suitable occasions (Presmeg, 1986, p. 42). The important role of visualisation that was identified within this paper led the researcher to conclude that encouraging visualisation during the learning and teaching of data handling should be a significant part of the school mathematics curriculum on all grade levels. It should be noted that selection of activities that encourage visualisation should be done with great care and their implementation and usage must be carefully planned. In order for mathematics teachers to appreciate the role of visualisation, the teachers themselves need to be aware of the role that visualisation plays in the teaching and learning of mathematics. This research made the teachers aware of the role of visualisation but there is need for more research to be done in order to improve teachers' visualisation skills in data handling. By ignoring visualisation, curricula not only fail to engage a powerful part of learners' minds in service of their mathematical 
thinking, but also fail to develop learners' skills at visual exploration and argument.Lastly the study appears to have managed to identify the role of visualisation through the description of the thought processes that learners go through while solving data handling problems. It can therefore be expected with some confidence that at least a part of the findings can be generalised to other situations that satisfy these requirements.

\section{References}

Ainley, J., \& Pratt, D. (2001). Introducing a special issue on constructing meaning from data. Educational Studies in Mathematics, 45, 1-8.

Arcavi, A. (2003). The role of visual representations in the learning of mathematics. Educational Studies in Mathematics, 52(3), 215-241.

Aspinwall, L., Shaw, K. L., \& Presmeg, N. C. (1997). Uncontrollable mental imagery: Graphical connections between a function and its derivative. Educational Studies in Mathematics, 33,301-317.

Bishop, A. J. (1989). Review of research on visualisation in mathematics education. Focus on Learning Problems in Mathematics, 11(1), 7-16.

Burrill, G., \& Camden, M. (Eds.) (2006). Curricular development in statistics education: International Association for Statistical Education 2004 Roundtable. Voorburg, the Netherlands: International Statistical Institute and International Association for Statistical Education. Retrieved from http://www.stat.auckland.ac.nz/ iase/publications.

Cobb, P., Yackel, E., \& Wood, T. (1991). Curriculum and teacher development: Psychological and anthropological perspectives. In E. Fennema, T. P. Carpenter, \& S. J. Lamon (Eds.), Integrating research on teaching and learning mathematics (pp. 83-120). Albany, NY: SUNY Press.

Department of Education (2002). Revised national curriculum statement Grade R-9 (Schools), Overview. Pretoria: National Department of Education, South Africa.

Department of Education. (2003). National curriculum statement Grades 10-12 (General). Mathematics. Pretoria: National Department of Education.

Eisenberg, T., \& Dreyfus, T. (1991). On the reluctance to visualise in mathematics. In W. Zimmerman \& S. Cunningham (Eds.), Visualisation in Teaching and Learning Mathematics (pp. 1-8). Washington DC: Mathematical Association of America.

Fennema, E., \& Carpenter, T. P. (1998). New perspectives on gender differences in mathematics: An introduction. Educational Researcher, 27(5), 4-21.

Fischbein, E. (1987). The nature and role of visualisation and imagery in the teaching. Retrieved January 25, 2007, from http://www.soton.ac.uk/ dkj/bsrlmgeom/orts/K_Jones_et_al_June_1998.pdf.

Franklin, C., Kader, G., Mewborn, D. S., Moreno, J., Peck, R., Perry, M., \& Scheaffer, R. (2005). A curriculum framework for K-12 statistics education. GAISE report. American Statistical Association. Retrieved January 25, 2007, from http://www.amstat.org/education/gaise/.

Gal, I. (2002). Adult's statistical literacy. Meanings, components, responsibilities. International Statistical Review, 70(1), 1-25.

Gerber, R., Boulton-Lewis, G., \& Bruce, C. (1995). Children's understanding of graphic representations of quantitative data. Learning and Instruction, 5, 77-100.

Hawkins, A., Jolliffe, F., \& Glickman, L. (1992). Teaching statistical concepts, Harlow, Essex: Longman.

Kosslyn, M. S. (1994). Image and brain: The resolution of the imagery debate. London: W. W. Norton and Company.

Lajoie, S. P. (Ed.). (1998). Reflections on statistics: Learning, teaching, and assessment in grades K-12. Mahwah, NJ: Erlbaum.

Maher, C. A., \& Alston, A. (1989). Is meaning connected to symbols? An interview with Ling Chen. Journal of Mathematical Behaviour, 8, 241-248.

Makina, A. (2005). An investigation of the role of visualization in data handling in Grade 9 within a problemcentred context. (Unpublished masters dissertation). University of South Africa, Pretoria.

Moses, B. (1982). Visualization: A different approach to problem solving. School Science and Mathematics, $82,141-147$.

National Council of Teachers of Mathematics. (1989). Curriculum and evaluation standards for school mathematics: Reston, VA: NCTM.

National Council of Teachers of Mathematics. (2000). Principles and standards for school mathematics: An Overview. Reston, VA: NCTM. 
Owens, K. D. \&, Clements, M. A. K. (1998). Representations in spatial problem solving in the classroom. Journal of Mathematical Behavior, 17 (2): 97-218.

Presmeg, N. C. (1985). The Role of visually mediated processes in high school mathematics: A classroom investigation. (Unpublished doctoral dissertation). University of Durban-Westville, Durban.

Presmeg, N. C. (1986).Visualization in high school mathematics. For the Learning of Mathematics 6(3): 4246.

Presmeg, N. C. (1992). Different thinking styles. In M. Moodley, R. A. Njisane, \& N. C. Presmeg (Eds.), Mathematics education for pre-service and in- service teachers (pp. 38-44). Pietermaritzburg: Shuter \& Shooter.

Shaughnessy, J. M. (1992). Research in probability and statistics: Reflections and directions. In D. A.Grouws (Ed.), Handbook of research on mathematical teaching and learning (pp. 465-494). New York: Macmillan.

Scheaffer, R. L. (2006). Statistics and mathematics: On making a happy marriage. In G. Burrill (Ed.), Thinking and reasoning with data and chance. NCTM 2006 Yearbook (pp. 309-321). Reston, VA: NCTM.

Thornton, S. (2000). A picture is worth a thousand words. Retrieved February 7, 2003, from http/www.amt . Canberra.edu.au/-sjt/dva.htm.

Van den Berg, G. ( 2004).The use of assessment in the development of higher-order thinking skills. Africa Education Review, 1(2): 279-294.

Wheatley, G. H. (1991). Enhancing mathematics learning through imagery. Arithmetic Teacher, 39(1), 34-36.

Wild, C. J., \& Pfannkuch, M. (1999). Statistical thinking in empirical enquiry. International Statistical Review, 67(3), 223-265.

Zimmermann, W., \& Cunningham, S. (1991). Editor's introduction: What is mathematical visualization. In W. Zimmerman \& S. Cunningham (Eds.), Visualisation in teaching and learning mathematics (pp. 1-8). Washington, DC: Mathematical Association of America. 


\section{Appendix A}

Description of Kosslyn's categories of mental processes used for analysing data

\begin{tabular}{|c|c|}
\hline Process & Description of micro-strategies \\
\hline \multirow[t]{2}{*}{ Image generation } & $\begin{array}{l}\text { Occurs when a person recalls a picture or visual mental representation from long } \\
\text { term memory and placing that image in a central location within working memory. }\end{array}$ \\
\hline & $\begin{array}{l}\text { Multiple uses of materials. } \\
\text { (Incorporating new experiences) }\end{array}$ \\
\hline \multirow[t]{5}{*}{ Image inspection } & $\begin{array}{l}\text { Involves a focused mental scanning of the qualities of the image within working } \\
\text { memory. }\end{array}$ \\
\hline & $\begin{array}{l}\text { Results when one examines an image in order to answer questions about it (classify, } \\
\text { scrutinise). }\end{array}$ \\
\hline & Noticing similarities and differences in shapes (connection). \\
\hline & $\begin{array}{l}\text { Selectively attending to input, feedback from existing schemata (heuristic } \\
\text { processes): }\end{array}$ \\
\hline & $\begin{array}{ll}\text { - } & \text { establishing meaning of the problem } \\
\text { - } & \text { developing tactics } \\
\text { - } & \text { self-monitoring }\end{array}$ \\
\hline \multirow[t]{5}{*}{ Image transformation } & It is when one changes or operates upon an image: \\
\hline & - rotate \\
\hline & - zoom \\
\hline & $\begin{array}{l}- \text { translate } \\
- \text { scan }\end{array}$ \\
\hline & $\begin{array}{l}\text { Movement of images of shapes into related shapes } \\
\text { ( e.g., square to hexagon ) }\end{array}$ \\
\hline \multirow[t]{3}{*}{ Image use } & It occurs when an image is employed in the service of some mental operation. \\
\hline & Mental involvement in making the shape (refinement) \\
\hline & Making, using, changing and storing images, concepts, understanding and schemata. \\
\hline
\end{tabular}




\section{Appendix B}

\section{Task 1}

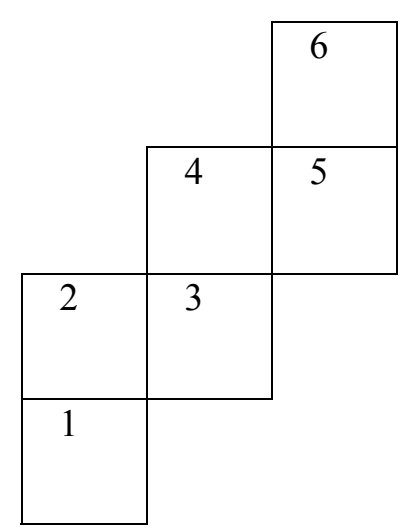

1. Identify the geometric body or image which could be obtained by imagining the folding back of the multi-dimensional drawing shown above.

2. On the plane piece of paper provided draw the image obtained by unfolding or folding the geometric body (actually perceived or mentally represented) by the figure above.

3. Clarify your diagram by indicating the number which will be opposite the other.

(Adapted from Fischbein, 1987)

\section{Task 2}

\section{Data Interpretation Question}

A well-known intersection in Armidale has had a number of serious accidents. The number of serious accidents was recorded for the last ten years.

$\begin{array}{cccccccccc}1981 & 1982 & 1983 & 1984 & 1985 & 1986 & 1987 & 1988 & 1989 & 1990 \\ 2 & 4 & 5 & 9 & 3 & 6 & 7 & 10 & 4 & 6\end{array}$

1. Describe any pattern that you can see in the data.

2. Approximately how many accidents would you expect in 1991? Why?

3. Suggest four other years in the future (after 1990) when you think the number of accidents might exceed 8 . Why did you select those years?

(Adapted from Chris Reading, University of New England, Australia)

\section{Task 3}

The learners in your class were asked to take note of the first 100 vehicles that passed by the school's main gate road in Pretoria. The numbers of each type of vehicle were given as follows:

$$
\text { lorry---7 bus---0 car---28 taxi---2; motor-bike---15 bicycle---48 }
$$

Represent the above information in a way you would like it displayed on a poster for the school noticeboard for all the people to see. Use the plane paper provided to draw your representation. Show on the paper provided all the steps you will take in order to draw your representation. Explain why you prefer this representation and not the others. 